\title{
Two new journals copy the old
}

\author{
Volunteer with publisher says duplication was a technical 'mistake'.
}

At least two journals recently launched by the same publisher have duplicated papers online that had been published elsewhere.

Late last year, an organization called Scientific Research Publishing reproduced the papers in what its website (www.scirp.org) billed as the first issues of the new journals Journal of Modern Physics and Psychology. HuaiBei Zhou, a physicist from Wuhan University in China who says he helps to run Scientific Research's journals in a volunteer capacity, says that the reproductions were a mistake caused by posting sample content for the new journals; links to the content have since been removed. And since Nature began its enquiries, the web pages of other journals published by Scientific Research have removed from lists of editorial boards the names of researchers who say they did not agree to such positions. Many of these people thought they had agreed to serve on the board for a different journal with a similar name.

Scientific Research recently e-mailed many academics to solicit articles for some of its 34 journals, including some that publish original research. However, what Scientific Research's website labelled as the first issue of the Journal of Modern Physics completely reproduced papers published in 2000 by Britain's Institute of Physics in the open-access New Journal of Physics ${ }^{1-3}$.

The Scientific Research journal Psychology also contains papers that seem to have been published previously, including one in its first issue that was awarded an Ig Nobel Prize in 2000 after being published elsewhere ${ }^{4}$. Marc Abrahams, organizer of the Ig Nobel awards, contacted Scientific Research in late December asking for more information about the new journal; the issue has since been removed from the website.

Neither Psychology nor the Journal of Modern Physics had an editor-in-chief listed on the site. But Zhou says that the duplications are information-technology "mistakes" that would be corrected. "They just set up the website to make it look nice," he says.

Scientific Research's website is registered in China, although Zhou says that the organization is based in the United States and is run from there and China. He says it was set up "three or four years ago" by a group of friends and colleagues from these countries to promote exchange between scholars. He declined to tell Nature who these people were or whether he was one of them, although in an e-mail to Abrahams he describes himself as president of Scientific Research.

\section{Legal consideration}

Those involved in the original publications of the physics papers say that they were not notified of Scientific Research's work. Tim Smith, senior publisher for the New Journal of Physics, says that even if the papers were being used

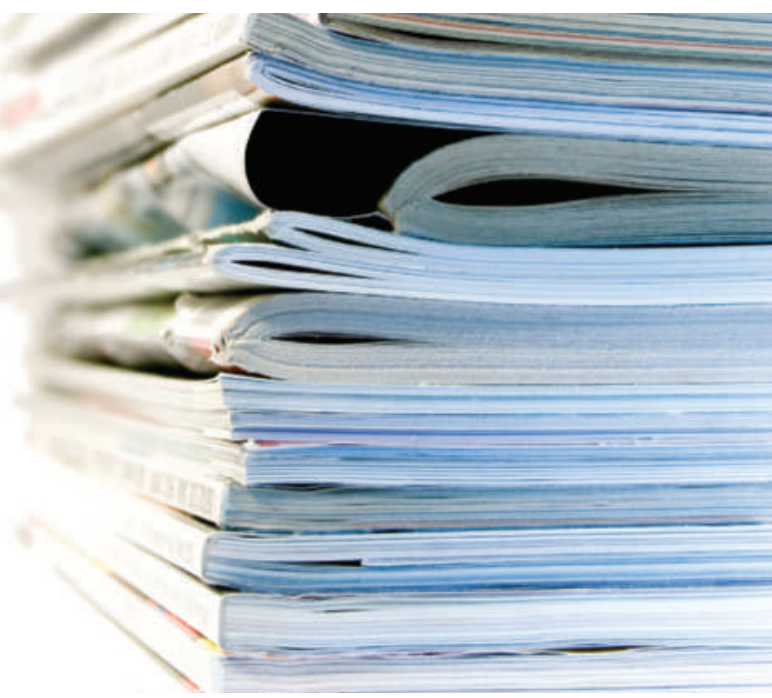

Some experts have withdrawn from new journals' editorial boards.

and not a psychiatrist or psychologist," he says, "so found it a bit strange."

Schiano's name has since been removed. So have other researchers once listed as editorial board members for Scientific Research's Journal of Biophysical Chemistry, such as Ruth Nussinov, a computational structural biologist at the National Cancer Institute in Frederick, Maryland, and Kwang-Soo Kim, a neurobiologist at Harvard Medical School based in Belmont, Massachusetts.

Zhou says that Scientific Research has e-mails from each scientist listed on the website agreeing to the position. Some of them say they thought they had agreed to be on the board of more established journals. "Because of my crazily busy schedule at that time, I did not carefully read their information and mistakenly thought that it was the Journal of Biological Chemistry," says Kim.

The home page for the Journal of Biophysical Chemistry contains only the titles and page numbers of four papers in the first issue. Identical paper titles appear in the Journal of Bioscience ${ }^{5-8}$, published by Springer India, from 2000.

Scientific Research's journal Natural Science seems to contain original research papers. A member of its editorial advisory board, James Chou from Harvard Medical School in Boston, Massachusetts, says that he was not aware that any Scientific Research jour-

to mock up a sample issue of a new journal, they should not have been repurposed without permission. In a PDF of the Journal of Modern Physics issue, all the Institute of Physics branding has been removed and replaced by Journal of Modern Physics branding and reference details; otherwise the papers are identical down to the typeface, font and formatting. Smith says that the institute is exploring potential legal action. "We are discussing it as a matter of urgency," he says.

Some academics have also questioned how they came to be added to online lists of advisory board members for various Scientific Research journals. For instance, Thomas Schiano of Mount Sinai Medical Center in New York received an e-mail from Scientific Research saying he was on the editorial board of Psychology. "I am a transplant hepatologist nals had reproduced any published articles, but says that the journals should "definitely retract the duplicate papers".

Zhou says that he stands by the organization. Copying articles "is not allowed", he says, and holds that he has "zero tolerance" for such practices.

\section{Katharine Sanderson}

1. Drescher, H. J., Hladik, M., Ostapchenko, S., Pierog, T. \& Werner, K. New J. Phys. 2, 31 (2000).

2. Kurizki, G., Kofman, A. G., Kozhekin, A. \& Harel, G. New J. Phys. 2, 28 (2000)

3. Behringer, K. \& Fantz, U. New J. Phys. 2, 23 (2000).

4. Kruger, J. \& Dunning, D. J. Pers. Soc. Psychol. 77, 1121-1134 (1999).

5. Mariappan, P., Balasundaram, C. \& Schmitz, B. J. Biosci. 25, 301-313 (2000)

6. Rehorek, S. J., Firth, B. T. \& Hutchinson, M. N. J. Biosci. 25, 181-190 (2000)

7. Mitra, D. \& Johri, M. M. J. Biosci. 25, 331-338 (2000).

8. Mariconda, S., Namgoong, S.-Y., Yoon, K.-H., Jiang, H. \& Harshey, R. M. J. Biosci. 25, 347-360 (2000). 